\title{
PERANAN AUDIT OPERASIONAL SUMBER DAYA MANUSIA TERHADAP EFEKTIVITAS KINERJA KARYAWAN PADA PT MEKAR LANGGENG
}

\author{
Dessy Herlisnawati \\ Dosen Tetap Fakultas Ekonomi Universitas Pakuan \\ Lecturer of Economic Faculty at Pakuan University
}

Asep Heri

Mahasiswa Fakultas Ekonomi Universitas Pakuan

Student of Economic Faculty at Pakuan University

\begin{abstract}
ABSTRAK
PT Mekar Langgeng, merupakan perusahaan yang bergerak di bidang infrastruktur dan jasa konstruksi. Banyaknya departemen yang terdapat pada PT Mekar Langgeng, sehingga harus adanya pengendalian tentang kinerja karyawan. Permasalahan yang terjadi di PT Mekar Langgeng, yakni kinerja karyawan tidak sesuai dengan harapan manajemen perusahaan. Penyebab tidak efektifnya kinerja karyawan adalah tingkat gaji, lingkungan kerja dan hubungan kerja dengan atasan maupun bawahan sesama rekan kerja. Metode analisis yang digunakan adalah Deskiptif Kualitatif dan Kuantitatif (Nonstatistik). Hasil penelitian dapat disimpulkan bahwa Audit operasional sumber daya manusia dilakukan oleh auditor yang kompeten, memiliki latar belakang pendidikan formal sesuai dengan tugasnya. Dalam penilaian kinerja karyawan PT Mekar Langgeng telah berjalan dengan baik dan sesuai dengan prosedur yang berlaku. Audit operasional sumber daya manusia berpengaruh terhadap efektivitas kinerja karyawan.
\end{abstract}

Kata Kunci: Audit Operasional Sumber Daya Manusia dan Efektivitas Kinerja Karyawan.

\begin{abstract}
PT Mekar Lasting, is a company in the field of infrastructure and construction services. Many departments on PT Mekar Lasting, so the control of the employee's performance should be exist. The problems that occurred in PT Mekar Lasting was the employee's performance does not match the expectations of company management. The cause of the ineffectiveness of the employee's performance is the level of salaries, working environment and working relationships with superiors and subordinates colleagues. The analytical method that be used is deskiptif Qualitative and Quantitative (Nonstatistik). The concluded that is the human resources operational audit carried out by auditors who are competent, have a background in formal education in accordance with his duties. In the assessment of the performance of employees of PT Mekar Lasting has been going well and in accordance with the applicable procedures. Operational audit of human resources is affected to the effectiveness of employee performance.
\end{abstract}

Keywords: Operational audit of human resources Human and Effectiveness of Employee Performance.

\section{Pendahuluan}

Pada dasarnya, perusahaan banyak mengalami maju mundurnya dalam melakukan usaha atau kegiatan yang ruang lingkupnya besar secara ideal menyelenggarakan aktivitas audit operasional untuk mengevaluasi pengendalian internal yang ada dalam perusahaan tersebut. Pengendalian intern harus ada, memadai, agar dilaksanakan dengan baik, diawasi serta disesuaikan dengan perkembangan perusahaan saat ini. Audit operasional merupakan alat bantu pengendalian manajemen dalam melakukan semua kegiatan perusahaan, sehingga kegiatan-kegiatan yang dilakukan manajemen perusahaan berjalan dengan efektif, efisien, dan ekonomis serta dapat mencapai tujuan yang telah ditetapkan.

Audit dilakukan terhadap setiap aspek kegiatan dan hasilnya memberikan 
rekomendasi dan verifikasi laporan hasil evaluasi kinerja karyawan. Audit operasional merupakan penelaah atas prosedur dan metode operasi perusahaan yang digunakan untuk menentukan apakah tujuan perusahaan mengenai efektivitas kinerja karyawan dicapai secara efektif, efisien, dan ekonomis.

Audit manajemen lazim dilakukan auditor interen PT Mekar Langgeng, secara periodic, Permasalahan yang terjadi pada PT Mekar Langgeng, kompetensi karyawan yang di bawah standar, hubungan yang kurang harmonis. Hal ini mengakibatkan kinerja karyawan tidak sesuai dengan target yang diharapkan PT Mekar Langgeng.

Adapun tujuan penelitian ini sebagai berikut: 1) Untuk mengetahui pelaksanaan audit operasional sumber daya manusia pada PT Mekar Langgeng; 2) Untuk mengetahui efektivitas kinerja karyawan yang dicapai pada PT, Mekar Langgeng; dan 3) Untuk mengetahui pengaruh audit operasional sumber daya manusia terhadap efektivitas kinerja karyawan pada PT Mekar Langgeng.

\section{Metode Penelitian}

Metode analisis yang digunakan adalah Deskiptif Kualitatif dan Kuantitatif (Nonstatistik), yaitu menggambarkan keadaan objek penelitian yang sebenarnya dengan mengumpulkan data yang relevan yang tersedia bersifat kualitatif maupun kuantitatif, kemudian disusun, dipelajari dan dianalisis lebih lanjut. Data yang diolah adalah Laporan kepuasan kerja karyawan dan laporan audit operasional dari tahun 2007 sampai dengan 2010.

\section{Hasil dan Pembahasan}

Dalam aktivitas PT Mekar Langgeng ada beberapa faktor yang mempengaruhi kinerja karyawan diantaranya adalah sebagai berikut:

1. Aspek SDM

Kegiatan pada bagian SDM atau tenaga kerja yang meliputi penyelenggaraan administrasi kepegawaian serta pendidikan dan pelatihan, penerimaan pegawai (kelengkapan surat lamaran, interview, ujian saringan), sistem kerja (pengaturan kerja, diklat), kesejahteraan (Gaji, Upah lembur, tunjangan dan fasilitas), menyelenggarakan administrasi kepegawaian yang mencakup pengangkatan, pemindahan, pemberhentian, kenaikan gaji atau pangkat, cuti pegawai, absensi pegawai dan lain-lain, meneliti, menghimpun dan melaksanakan administrasi kepegawaian, pengembangan karier dan pendidikan serta pelatihan pegawai, dan mempersiapkan dan menyusun syarat-syarat dan kualifikasi calon pegawai dan kualifikasi penempatan pegawai.

2. Waktu kerja dan status karyawan pada PT Mekar Langgeng :

a. Waktu kerja yang berlaku untuk tenaga kerja langsung dibagi menjadi 3 (tiga) shift, yaitu:

Tabel 3.1.

Waktu Kerja

Work Time

\begin{tabular}{|c|c|c|}
\hline No. & Keterangan & Pukul \\
\hline 1. & Non Shift & $08.00 \mathrm{~s} / \mathrm{d} 17.00$ \\
\hline 2. & Shift I & $07.00 \mathrm{~s} / \mathrm{d} 16.00$ \\
\hline
\end{tabular}




\begin{tabular}{|c|c|c|}
3. & Shift II & $17.00 \mathrm{~s} / \mathrm{d} 24.00$ \\
\hline 4. & Shift III & $24.00 \mathrm{~s} / \mathrm{d} 06.00$ \\
\hline
\end{tabular}

Sumber: PT Mekar Langgeng

b. Status Karyawan

Status karyawan merupakan hal yang terdapat dalam setiap perusahaan, baik itu manufaktur, konstruksi, jasa maupun dagang, hal ini yang nantinya menjadi pertimbangan dalam penggajian karyawan perusahaan dan status karyawan ini dibedakan menjadi :

a) Karyawan tetap

b) Karyawan kontrak

c) Karyawan harian

c. Gaji

Gaji yang diberikan setiap bulannya dibedakan menurut status karyawan, yang terdiri atas:

1) Untuk karyawan tetap terdiri dari :
a) Gaji Pokok
b) Tunjangan Jabatan.
c) Tunjangan Kemahalan.
d) Tunjangan Prestasi.
e) Tunjangan Keluarga.
f) Tunjangan Produksi.

2) Untuk karyawan kontrak hanya menerima gaji, tanpa memperoleh tunjangan-tunjangan.

3) Untuk karyawan harian besarnya gaji yang diterima berdasarkan besarnya upah per hari dikalikan dengan hari hadir.

4) Lembur

Lembur adalah upah yang diberikan kepada setiap tenaga kerja langsung yang bekerja lebih dari jam kerja normal perhari.

\section{Kesimpulan}

Dari pembahasan pada bab sebelumnya terdapat hal-hal sebagai berikut:

1. Audit operasional sumber daya manusia dilakukan oleh auditor yang kompeten, memiliki latar belakang pendidikan formal sesuai dengan tugasnya. Keberadaan audit internal kedudukannya terpisah dari divisi yang di audit sehingga kedudukannya independen. Rekomendasi yang diberikan auditor internal terkait kinerja karyawan antara lain sebagai berikut:

a. Pimpinan Divisi maupun pimpinan proyek melakukan pengawasan terhadap kinerja karyawan, baik jam kerja maupun tugas kerja (job description).

b. Karyawan yang memiliki prestasi pada tahun berikutnya akan diberikan kompensasi atau balas jasa berupa promosi menjadi karyawan tetap (bagi karyawan kontrak) dan kenaikan jabatan atau tingkatan bagi karyawan tetap dan bagi karyawan yang prestasinya menurun akan mendapatkan sanksi. 
c. Kepala / pimpinan divisi sumber daya manusia harus menyimpan back-up laporan hasil kinerja karyawan yang dilakukan setiap 3 bulan sekali, agar informasi yang dimiliki oleh manajemen atau divisi sumber daya manusia lebih lengkap.

2. Dalam penilaian kinerja karyawan PT Mekar Langgeng telah berjalan dengan baik dan sesuai dengan prosedur yang berlaku. Dari pemeriksaan yang telah dilakukan auditor internal terhadap kinerja karyawan, temuan yang dikemukakan secara khusus oleh audit internal adalah sebagai berikut:

a. Belum adanya sanksi tegas terhadap karyawan yang kerjanya tidak sesuai dengan standar perusahaan atau prestasi kerjanya menurun.

b. Tidak adanya data historis yang disimpan oleh sumber daya manusia mengenai kinerja karyawannya.

3. Audit operasional sumber daya manusia berpengaruh terhadap efektivitas kinerja karyawan. Pengaruhnya dapat terlihat pada formulir pencapain kinerja yang dilaporkan oleh kepala divisi masing-masing. Hal ini tentunya berkat penerapan rekomendasi yang diberikan oleh Audit Internal kepada divisi sumber daya manusia dan lembaga diklat yang sebelumnya diberikan audit internal.

\section{DAFTAR PUSTAKA}

Amin Widjaja Tunggal. 2010. Dasardasar Audit mnajemen. Jakarta: Harvarindo.
Arens, Alvin A., Randal J Elder, dan Mark S. Beasley. 2006. Auditing and Assurance Services: An Integrated Approach. USA: Pearson Prentice Hall.

Arens, Elder, Beasley. 2008. Auditing dan Pelayanan Verifikasi. Edisi 12. Jilid I dan II. Jakarta: Gramedia.

IBK Bhayangkara. 2008. Audit Manajemen: Prosedur dan Implementasi. Jakarta: Salemba Empat.

Ikatan Akuntan Indonesia. 2011. Standar Akuntansi Keuangan per 1 Januari 2011. Jakarta: Salemba Empat.

Indra Bastian. 2006. Sistem Akuntansi Sektor Publik. Edisi 2. Jakarta: Salemba Empat.

Istijanto. 2008. Riset Sumber Daya

Manusia. Jakarta: PT Gramedia Pustaka Utama.

Kasmir. 2009. Analisis Laporan Keuangan. Jakarta: Raja Grafindo Persada.

Kumaat, G Valery. 2011. Internal Audit. Jakarta: Erlangga.

Sawyer, Lawrence B., Mortimer A. Dittenhofer, dan James $\mathrm{H}$. Scheiner. 2005. Audit Internal Sawyer. Edisi 5. Alih Bahasa: Desi Adhariani. Buku 1. Jakarta: Salemba Empat. 